\title{
SOME STUDIES ON DESIGN, ANALYSIS AND MANUFACTURING ASPECTS OF SURFACE TO AIR ARTICLE LAUNCHING CANISTER
}

\author{
G. CHANDRAMOULI ${ }^{1}$, P. RAVINDER REDDY ${ }^{2}$, P. LAXMINARAYANA ${ }^{3} \&$ PRASAD SHIVDAS $^{4}$ \\ ${ }^{l}$ Former Programme Director, Defence Research and development Laboratory, Hyderabad, India \\ ${ }^{2}$ Principal, Chaitanya Bharati Institute of Technology, Hyderabad, India
}

${ }^{3}$ Professor, Department of Mechanical Engineering, College of Engineering (A), Osmania University, Hyderabad, India

${ }^{4}$ Scientist, Research and Development Establishment (Engineers), Pune, India

\begin{abstract}
Surface to Air Guided Flight Articles are launched to intercept and destroy incoming enemy attacking fighter aircrafts, helicopters, unmanned aerial vehicles etc. These articles are generally stored in containers with slight positive pressure such that the articles are protected from external environment conditions to use them for longer periods. The containers used for storing and launching are generally called launch canisters. It is essential to design these launch canister to enable the articles to be loaded, connected electrically and mechanically with a facility to check the health of articles and also launch them remotely in the prescribed direction. The canister size must be as small as possible and it should also be light in weight to facilitate accommodating as many canisters as possible on a single mobile self propelled vehicle. The canister design must also cater for the movement of article during launching and protect its control surfaces which are generally folded and kept during storage, transportation. Applicable load conditions, design considerations, canister configuration and its manufacturing aspects etc are discussed. The clearances that are required to be considered between some parts of moving article and launch canister was studied. A metallic canister is designed with Aluminum alloy material sheets and for withstanding various transportation loads, stacking loads, acceleration and deceleration loads including loads due to articulation of launcher in azimuth and elevation angles. A novel construction is adopted in canister structure to withstand for internal pressure requirement. The launch canisters of smaller in cross section and more than four meter in length are manufactured using number of jigs and fixtures meeting stringent alignment requirements. Structural analysis is carried out for various applicable load cases using finite element modeling using ANSYS software. In addition, effect of impingement of plume in canister while the article is travelling inside is also studied using Computational Fluid Dynamics methods. Various types of hatch covers of launch canister studied for their advantages and disadvantages. The realized launch canisters have been successfully used in live firing thus validating their design adequacy.
\end{abstract}

KEYWORDS: Positive Pressure, External Environment, Self Propelled, Plume Effect \& Unmanned Aerial Vehicles

Received: Jun 09, 2020; Accepted: Jun 29, 2020; Published: Aug 01, 2020; Paper Id.: IJMPERDJUN2020568

\section{INTRODUCTION}

Surface to Air Guided flying Articles are the potent, cost effective and efficient weapons to neutralize the intentions of enemy attacking fighter aircrafts and destroy them before commencement of release of any weapons. Generally these articles are stored in containers and protected from external environment conditions like dust, temperature, humidity, vibrations, bump, shock loads during transportation etc. These containers are loaded on mobile launchers and used for launching the articles in shortest possible time frames. Some articles are launched in vertical position and some are in slant variable launch angles depending on the functional requirements. 
The configuration of canister is selected based on the configuration of particular article and type of launching like rail, hot launched or cold or pop up launched etc. Generally metallic canisters are employed for storage, handling, transportation and launch of smaller sized articles so that it meets the parameters like strength to weight criteria, ease of fabrication, reusability etc. points. To meet this requirement, proper sealing material and configuration of opening/closing mechanisms need to be selected. To have good sealing arrangement for longer duration, it is desirable to have as minimum number of openings as possible. The front and rear hatches also need to be designed which can be easily opened /closed without manual intervention. The launch canisters are designed to keep under long term storage creep loads [1] and slight positive pressure to facilitate longer shelf life of articles. The canisters also need to be designed to withstand high temperature and high pressure gaseous [6] flow conditions. Sometimes certain type of electro mechanical or electroexplosive devices are used for opening the front or rear hatch covers. Some rupturable [2] covers with mechanismsto break [5] them in a single time operation are also designed for launch canisters.Each design has some advantages and some minor disadvantages. Depending on the operational requirements these designs can be frozen. Few canisters are designed to be accommodated to be housed in modular [11] assemblies. To reduce the stresses at corners, some canisters are designed in polygonal [10] shaped constructions. To keep the umbilical connected during entire duration and to facilitate its withdrawal during launching, a suitable rugged mechanism needs to be adopted. During the launching, this mechanism should not come in the way of travelling article. Different retraction mechanisms are selected for different type of umbilical configurations. The mechanisms selected for umbilical retraction should also not get disturbed during long durations of transport on different terrain dynamic conditions. In addition, the articles must be easily loadable/unloadable in to the canister and must be electrically connectable/disconnectable as and when required. Canister should have facility for easy loading / unloading of it on the launcher.

The hot launch canisters generally have atleast two openings, one in front/top opening and a rear/bottom opening. For some specific applications few canisters are housed together in a box like configuration with a common exhaust duct [7] to minimize effect of plume on the surroundings. Slant launched guided article is designed to be held in the launch rail by using atleast two launch lugs passing through a launch rail. The aerodynamic control surfaces (wings and fins) of article are in folded condition inside the canister to save the volume and to facilitate accommodating more articles per one launcher. As the guided flying article comes out of the canister, wings and fins are unfolded automatically with the help of the springs.

\section{SOME DESIGN CONSIDERATIONS OF ARTICLE LAUNCHING CANISTER}

Following points need to be considered while designing the canister of any flying articles:

a) Size, shape and geometrical considerations

For slant launched articles the canisters are designed in square tubular configurations for articles of low mass and travels at speeds of higher than 10-15 m/s. This configuration also facilitates accommodation of rails and folded control surfaces. The shape of canister is generally cylindrical in case of articles with high mass and travels slowly of the order of $3-5 \mathrm{~m} / \mathrm{s}$ speed.

b) Selection of material and manufacturing process

The smaller sized canisters up to the size of $500 \times 500 \mathrm{~mm}$ are generally metallic with sheet metal formed and welded constructions. Depending on the duration of travel of the article inside canister and the overall temperature increase 
is estimated for a selected material under the impingement of plume of the article. For articles with higher than about 1000 $\mathrm{mm}$ in radius or squares, it is generally preferred to opt for fiber reinforced plastics with either filament wound manufacturing or compression molded manufacturing process. This will facilitate lighter overall article and canister mass and helps in going for ease of handling equipments. The thickness of the canisters must be selected based on the stiffness requirements for various handling loads and transportation loads. Quantities vis a vis recyclability of material may also need to be considered with reference to environment hazards.

c) Sealing design

For metallic canisters the thickness of rubber sealing material is generally lower. For composite canisters the thickness of rubber sealing materials are generally higher to accommodate distortions of canister under pressure loads. Configuration of hatch door should have facility for sealing under positive pressure. It should be able to be closed/assembled easily with the canister. Automatic opening and closing feature is preferred. If penetratable front and rear hatch covers are required to be designed, then proper materials to be selected for impact, pressure and plume loads.

d) Canisters should be designed to withstand external environment conditions like high temperature of the order of +70 Deg C, Low temperatures of the order of -40 Deg C, Relative humidity of 95\%, Under extreme dusty, wind conditions, handling / transportation loads up to $+/-3 \mathrm{~g}$ etc.

e) To be able to accommodate umbilical connector (electrical connector) retraction Mechanism.

f) To have appropriate guide to facilitate undisturbed travel of folding wings and folded fins inside the canister.

g) Guide rail and launch shoe configurations should be such that the locking and unlocking of article for various transportation and launching loads is feasible.

h) Should be able to withstand the pressure and temperature of the plume from the article.

\section{CONFIGURATION OF LAUNCH CANISTER}

The cross sectional configuration of the article launch canister under study is shown in figure 1. A square shaped canister is configured with a plainAluminium alloy sheet metal inside and reinforced outside with a corrugated Aluminium alloy sheets, to withstand internal pressure loads and loads due to handling, transportation, articulation, article launch. A mono guide rail is provided to guide the article with two launch shoes during launching. The launch canister was also configured to facilitate fixing of it with launch beam of launcher through bolting arrangement at four points. Similarly points for lifting with a lifting beam and forklift were also provided. Support pads are provided to have appropriate contact with the launch beam at the intended points. For supporting the folded fins and wings during launching, contact guides are provided in the sides. Guides are also provided to facilitate stacking of launch canisters.

The configuration of guide rail was chosen such a way to facilitate (i) constrain/arrest movement of the article launch shoes during transportation, erection, handling and launch of the article (ii) to provide easy, smooth movement of article for about 4 meters (iii) with a target weight budget of less than $200 \mathrm{~kg}$. The launch canister is modeled with 3D Solid works software. 


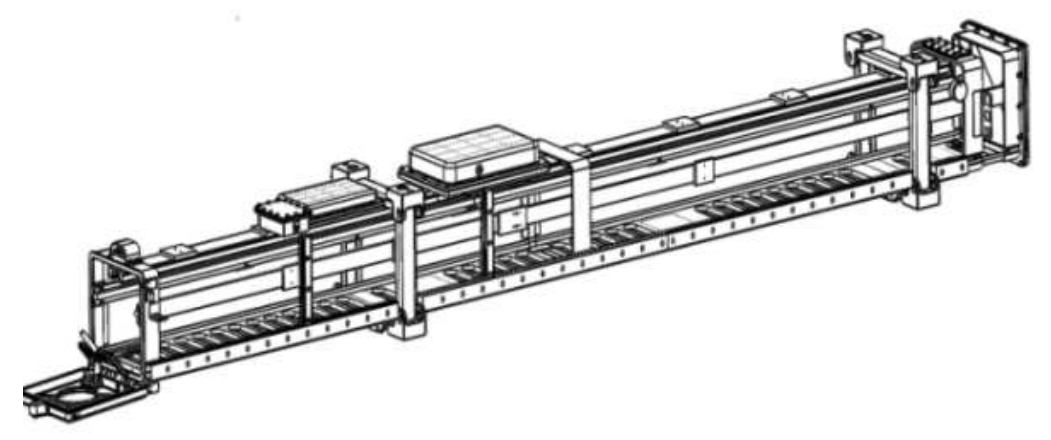

Figure 1: Structural Configuration of an Article Launch Canister.

\section{STRUCTURAL ANALYSIS OFLAUNCH CANISTER}

Structural analysis of launch canister is carried out with an objective of checking its suitability for adequate strength and rigidity under various loads and operating conditions of the system. Structural analysis has been carried out using ANSYS 14.0 FEA software. Idealization of finite elements is done with 4 nodded shell element (shell 63) with six degrees (3 transnational \& 3 rotational) of freedom per node. The launch canister is supported at four locations on the erecting and all the DOF are constrained at these four locations. Canister Embossed sheet ( $4 \mathrm{~mm}$ thickness)is meshed using shell element.

a) Material: Al Alloy 5083 sheets,

b) Material Properties: UltimateTensile Strength of $240 \mathrm{~N} / \mathrm{mm}^{2}$, Modulus of Elasticity E of 70GPa, Poisson's Ratio (v) of 0.3 , Mass density (p) of $2700 \mathrm{~kg} / \mathrm{m}^{3}$.

c) Design Load cases for canister analysis: Internal pressure of 0.5 bar, Static horizontal condition, static inclined condition, transportation ( $2 \mathrm{~g}$ vertical, $3 \mathrm{~g}$ longitudinal, $1.5 \mathrm{~g}$ horizontal conditions), handling (lifting) conditions, two canisters stacked one over the other, canister including the article weight. Wind loads acting on the stack of canisters, forces acting due to simultaneous slope in longitudinal and lateraldirection, Loads due to centrifugal and inertial.

\subsection{Loads on Canister Due to Transportation}

The body force always acts at the centre of mass of the body towards the earth's centre. Because the Launch platform can be oriented in the space due to ground slopes in roll and pitch, so it will experience a spatial loading.
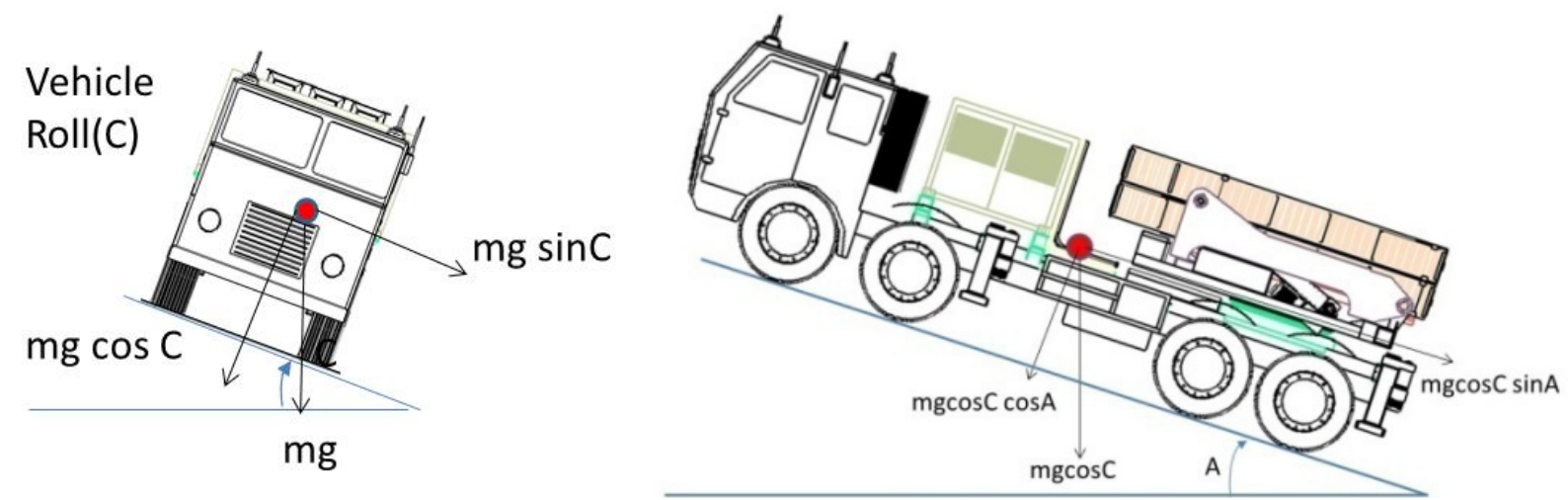

Figure 2: Launcher Roll Orientation. $\quad$ Figure 3: Launcher in Pitch Orientation. 
a) Body Force components due to simultaneous pitch and roll

Force Comp.due to Vehicle Roll \& Pitch :

$\left[\begin{array}{l}F_{x} \\ F_{y} \\ F_{z}\end{array}\right]=m g\left[\begin{array}{c}\sin C \\ \cos A \cos C \\ \cos C \sin A\end{array}\right]$

Force Comp. due to Azimuth Motion:

$\left[\begin{array}{l}F_{x} \\ F_{y} \\ F_{z}\end{array}\right]=m g\left[\begin{array}{ccc}\cos \gamma & 0 & \sin \gamma \\ 0 & 1 & 0 \\ -\sin \gamma & 0 & \cos \gamma\end{array}\right]\left[\begin{array}{c}\sin C \\ \cos A \cos C \\ \cos C \sin A\end{array}\right]=\left[\begin{array}{c}\cos \gamma \sin C+\sin \gamma \cos C \sin A \\ \cos A \cos C \\ -\sin \gamma \sin C+\cos \gamma \cos C \sin A\end{array}\right]$

Force Comp.ElevationMotion:

$\left[\begin{array}{l}F_{x} \\ F_{y} \\ F_{z}\end{array}\right]=m g\left[\begin{array}{ccc}1 & 0 & 0 \\ 0 & \cos \theta & -\sin \theta \\ 0 & \sin \theta & \cos \theta\end{array}\right]\left[\begin{array}{c}\cos \gamma \sin C+\sin \gamma \cos C \sin A \\ \cos A \cos C \\ -\sin \gamma \sin C+\cos \gamma \cos C \sin A\end{array}\right]$

Finally Resolution of Body Forces Along Principle Axis:

$\left[\begin{array}{l}F_{x} \\ F_{y} \\ F_{z}\end{array}\right]=m g\left[\begin{array}{c}\cos \gamma \sin C+\sin \gamma \cos C \sin A \\ \cos \theta \cos A \cos C-\sin \theta(-\sin \gamma \sin C+\cos \gamma \cos C \sin A) \\ \sin \theta \cos A \cos C+\cos \theta(-\sin \gamma \sin C+\cos \gamma \cos C \sin A)\end{array}\right]$

Where ' $A$ ' is pitch angle in degrees, ' $C$ ' is roll angle in degrees, ' $\theta$ ' is elevation angle in degrees and ' $\gamma$ ' is azimuth angle in degrees

\section{b) Forces due to acceleration/deceleration}

The vehicle is considered accelerating/decelerating in $\mathrm{z}$ direction. The launcher vehicle moves in pitch, roll, azimuth and elevation directions, the resulting forces act in $\mathrm{x}, \mathrm{y}$ and $\mathrm{z}$ directions.

\section{c) Centrifugal Force due to Vehicle Turning}

Considering that the vehicle is turning with radius $r_{v}$ during simultaneous elevation and azimuth motions, the centrifugal force due to vehicle turning is represented. Where $\mathrm{F}_{\mathrm{cv}}=\mathrm{mr}_{\mathrm{v}} \omega_{\mathrm{v}}{ }^{2}, \mathrm{~m}=$ is mass of any component, $\mathrm{r}_{\mathrm{v}}=\mathrm{vehicle}$ turning radius, $\omega_{\mathrm{a}}=$ Angular rate of any component with respect to turning center. Due to vehicle roll, launcher azimuth, pitch and launcher elevation motions, this force, $\mathrm{F}_{\mathrm{cv}}$ will be acting in principal $\mathrm{x}, \mathrm{y}$ and $\mathrm{z}$ direction.

Following input parameters are used for design/analysis:

In elevation, Angular rate ( $\omega \mathrm{e}$ ) of $7 \mathrm{deg} / \mathrm{sec}$ Angular Acceleration ( $\alpha \mathrm{e}$ ) of $7 \mathrm{deg} / \mathrm{sec}^{2}$ is used as per the launcher servo drive design. Similarly, in azimuth motion, angular rate of $20 \mathrm{deg} / \mathrm{sec}$ and angular acceleration of $20 \mathrm{deg} / \mathrm{sec}^{2}$ are used as per azimuth servo drive design. Vehicle turning radius of $14.5 \mathrm{~m}$, speed of $40 \mathrm{kmph}$, forward speed of $80 \mathrm{kmph}$, wind direction angle of $45 \mathrm{deg}$ and wind velocity of $33 \mathrm{~m} / \mathrm{s}$ are used for the analysis. Max pitch angle and roll angle of 5 degrees.

\section{FEA MODELING AND MESHING}


Element used in the analysis is 4 nodded shell element (shell 63) which has 6 DOF per node (3 translational \& 3 rotational). Both the modeling and meshing of the canister is done using Ansys 14.0 software. The FEA surface modeling is shown in the figure below:

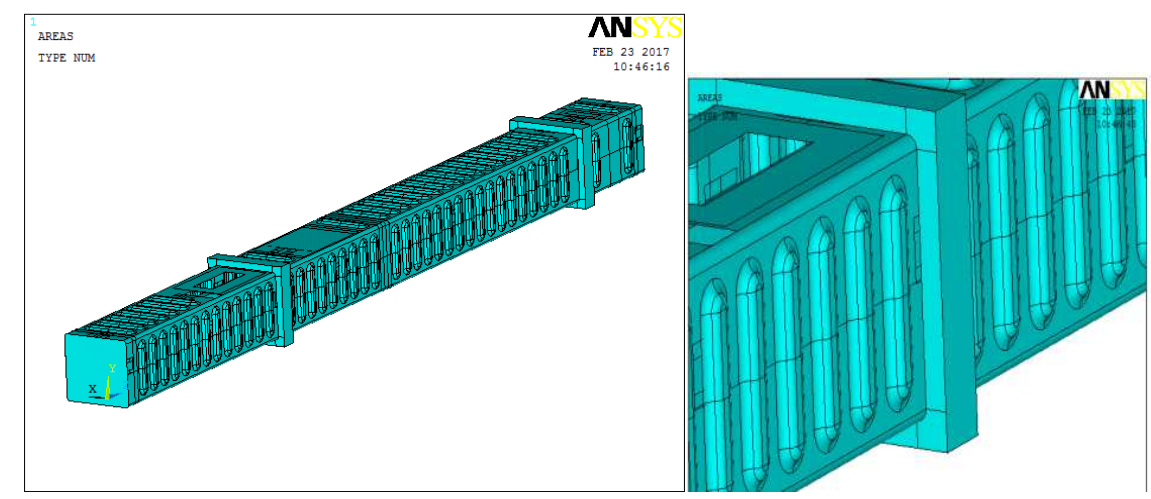

Figure 4: FEA Surface Model.
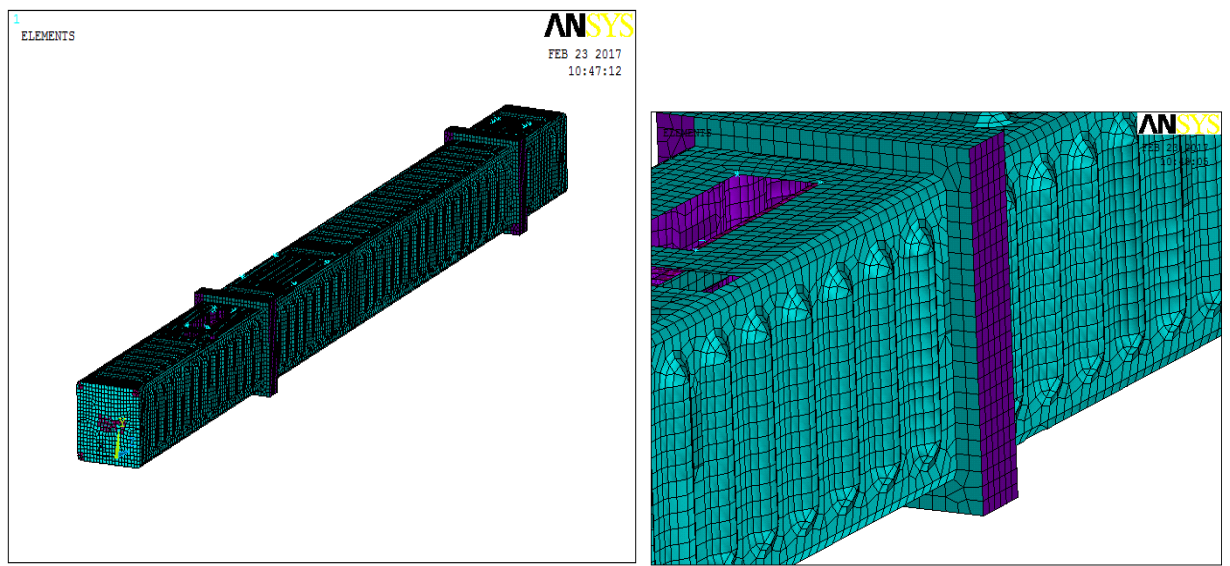

Figure 5: FEA Mesh Model.

The load cases boundary conditions and the results are shown in the subsequent paragraphs. The FEAmesh model is shown in the figure below. The surface model is meshed using Shell 63 element.

\section{Load Case 1: Static with positive Internal Pressure of 0.2 bar (g)}
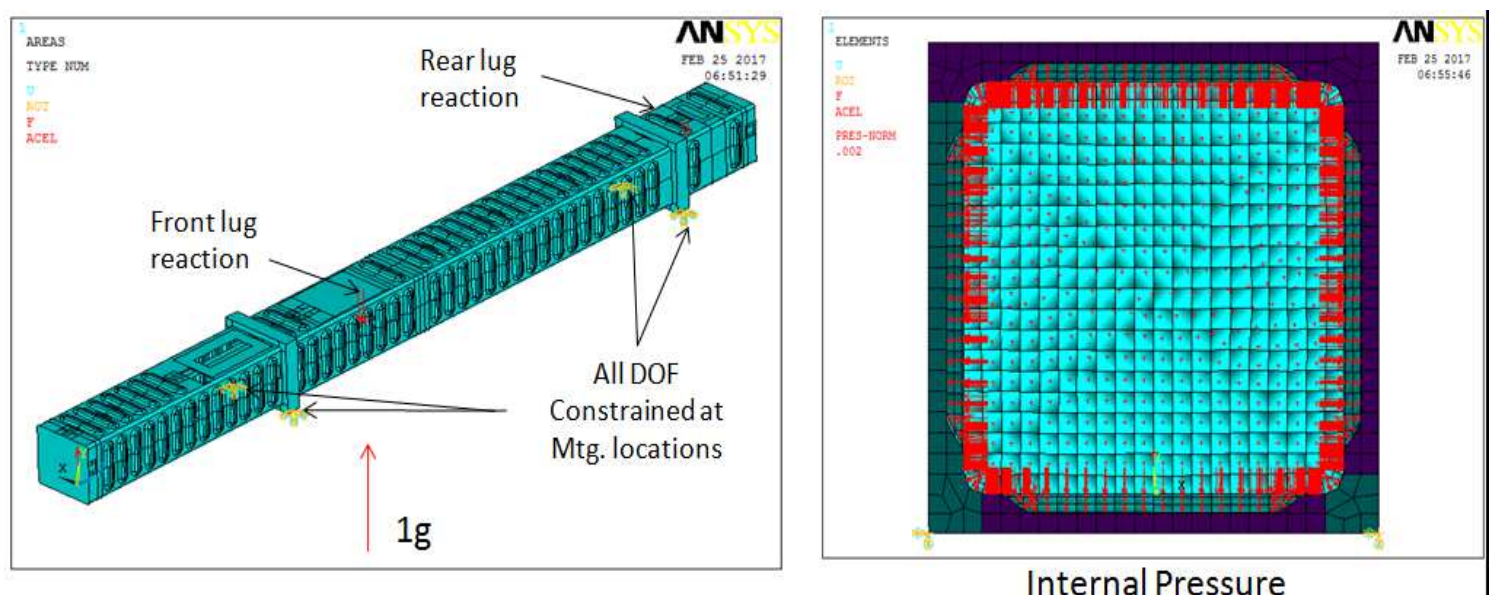

Figure 7: Boundary Conditions for Load Case: Static with Internal Pressure of 0.2 Bar. 


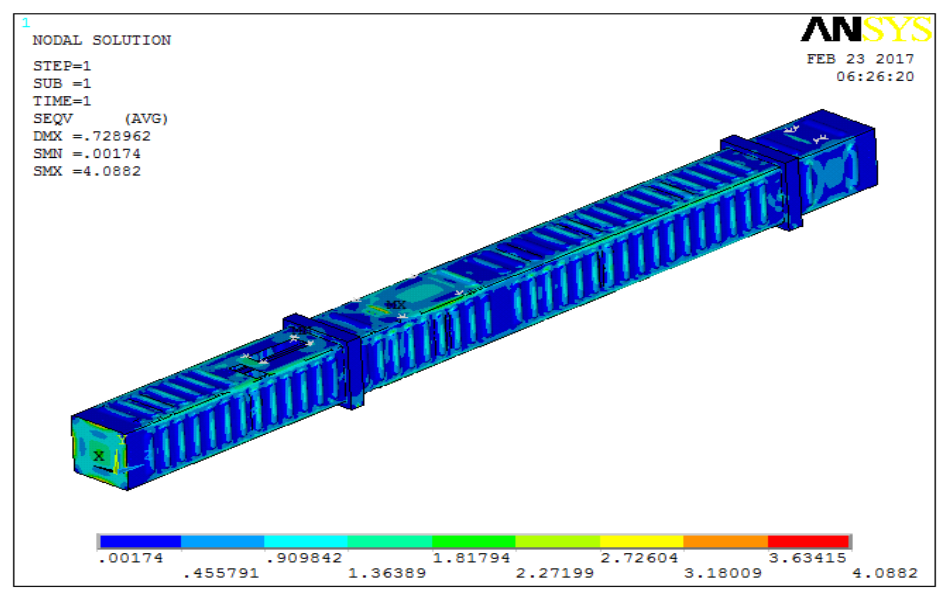

Figure 8: Stress Plot for Static with Internal Pressure of 0.2 Bar (g).
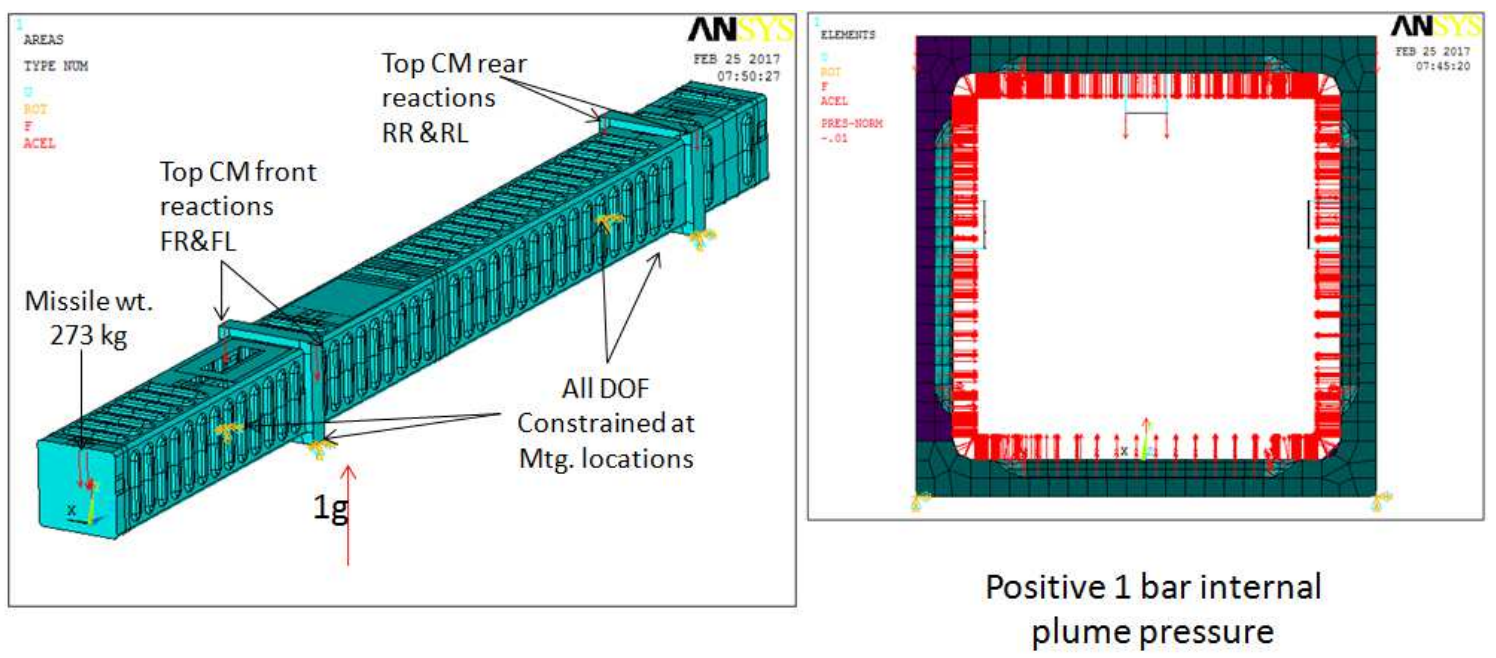

Figure 9: Boundary Conditions for Load Case: Static with Internal Pressur of 0.2 Bar.

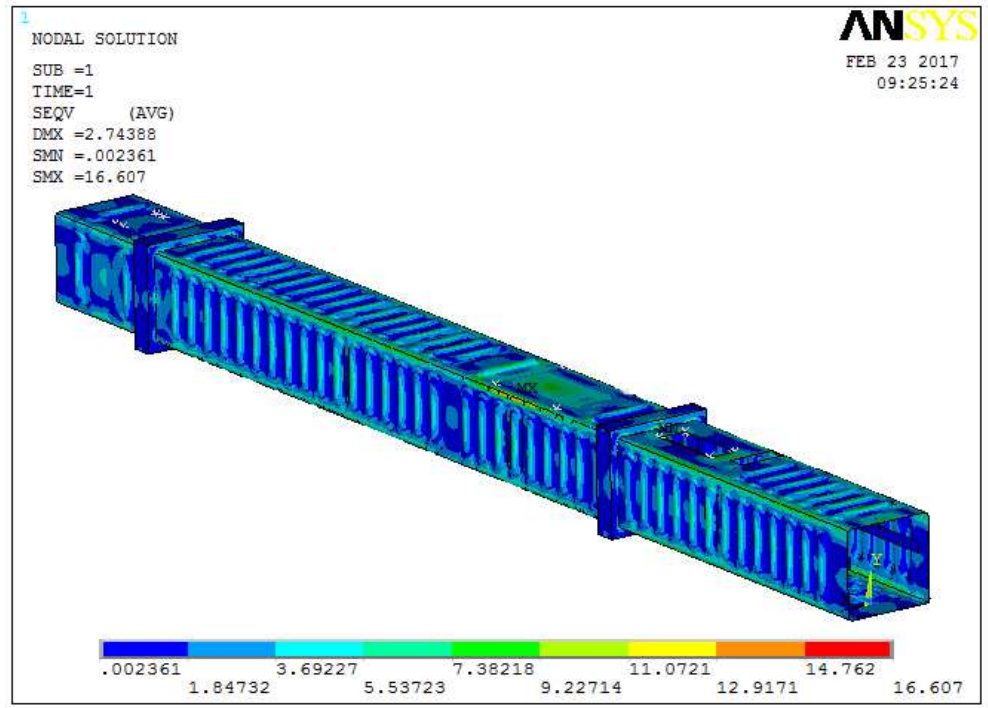

Figure 10: Stress Plot for Load Case 2d: Article Launch Suction due to High Plume Velocity and Article at the Tip of Canister. 
Table1 1: Summary of Structural Analysis Results

\begin{tabular}{|c|c|c|c|c|}
\hline Load Case & $\begin{array}{l}\text { Load } \\
\text { Case } \\
\text { No. }\end{array}$ & Load Considered & $\begin{array}{l}\text { Max } \\
\text { Stress } \\
\text { (MPa) } \\
\end{array}$ & $\begin{array}{c}\text { Safety } \\
\text { Margin }\end{array}$ \\
\hline \multirow{3}{*}{ Transportation } & $1 \mathrm{a}$ & $\begin{array}{ll}\checkmark & \text { Vertical 2g } \\
\checkmark & \text { Internal Pressure of } 0.2 \text { bar }(\mathrm{g}) \\
\checkmark & \text { Article lug reactions } \\
\checkmark & \text { Stacking load } \\
\end{array}$ & 120.1 & 1.63 \\
\hline & $1 b$ & $\begin{array}{ll}\checkmark & \text { Longitudinal 3g } \\
\checkmark & \text { Internal Pressure of } 0.2 \text { bar }(\mathrm{g}) \\
\checkmark & \text { Article lug reactions } \\
\checkmark & \text { Stacking load }\end{array}$ & 67.63 & 2.89 \\
\hline & $1 \mathrm{c}$ & $\begin{array}{ll}\checkmark & \text { Lateral } 1.5 \mathrm{~g} \\
\checkmark & \text { Internal Pressure of } 0.2 \text { bar }(\mathrm{g}) \\
\checkmark & \text { Article lug reactions } \\
\checkmark & \text { Stacking load }\end{array}$ & 73.62 & 2.66 \\
\hline \multirow{4}{*}{ Article Firing } & $2 \mathrm{a}$ & $\begin{array}{ll}\checkmark & \text { Plume pressure }+1 \text { bar (g) } \\
\checkmark & \text { Article lug reactions } \\
\checkmark & \text { Stacking load } \\
\end{array}$ & 162.2 & 1.2 \\
\hline & $2 b$ & $\begin{array}{ll}\checkmark & \text { Plume pressure }+1 \text { bar (g) } \\
\checkmark & \text { Article lug reactions at CM tip } \\
\checkmark & \text { Stacking load }\end{array}$ & 165.1 & 1.18 \\
\hline & $2 \mathrm{c}$ & $\begin{array}{ll}\checkmark & \text { Plume pressure }-1 \text { bar }(\mathrm{g}) \\
\checkmark & \text { Article lug reactions } \\
\checkmark & \text { Stacking load }\end{array}$ & 168.9 & 1.16 \\
\hline & $2 d$ & $\begin{array}{ll}\checkmark & \text { Plume pressure }-1 \text { bar (g) } \\
\checkmark & \text { Article lug reactions at CM tip } \\
\checkmark & \text { Stacking load } \\
\end{array}$ & 166.1 & 1.18 \\
\hline
\end{tabular}

In addition, analysis also performed for cases like solar radiation, effect of altitude of $3.5 \mathrm{~km}$, handling loads, static storage conditions in which the maximum stress record, deflections are observed to be lower than the above cases.

\section{d) Clearance studies}

The design of launch canister should also cater for adequate clearances between canister and the article during its launching process. A detailed tip off analysis is carried to find the angle of tilt of the article due to thrust misalignment, wind force, lateral shift of centre of mass, force due to umbilical retraction event while the article comes out of the launch canister. The analysis is carried out in four stages. In stage one when the article is traveling with both launch lugs in guide rail. In stage two, when the article is out of guide rail with front launch lug and rear lug in the guide rail. In stage three the rear lug also comes out of canister guide rail but some portion of article still inside the launch canister. In stage four, the end portion of article is completely out of canister. Since the article is required to be launched at various elevation angles starting from 10 to 60 degrees, the studies are carried out with respect to time of travel of article inside canister considering variation of some of the important parameters like thrust misalignment, lateral shift of centre of mass, variation of thrust, wind force etc. The results of these studies carried out for 10 degrees elevation angle are given in Table 1 and Fig 10. These studies are important for finalizing the design of launch canister. Max. Localized stress and deflection in this case are found to be $169 \mathrm{~N} / \mathrm{mm}^{2}$ and $3.18 \mathrm{~mm}$ respectively. 
Table 1: Tip off Analysis Results for Launch at 10 Deg

\begin{tabular}{|c|c|c|c|c|c|c|c|c|c|c|c|c|c|c|}
\hline \multirow{2}{*}{$\begin{array}{r}\text { Time } t \\
\text { Sec } \\
\end{array}$} & \multirow{2}{*}{$\begin{array}{r}\text { Angular } \\
\mathrm{Acc} \\
\alpha \mathrm{rad} / \mathrm{s}^{2}\end{array}$} & \multirow{2}{*}{$\begin{array}{c}\text { Pitch } \\
\text { Rate } \\
\omega \\
\mathrm{rad} / \mathrm{s} \\
\end{array}$} & \multirow{2}{*}{$\begin{array}{c}\text { Pitch } \\
\text { Rate } \omega \\
\text { Deg/S }\end{array}$} & \multirow{2}{*}{$\begin{array}{r}\text { Pitch } \\
\text { angle } \theta \\
\text { rad }\end{array}$} & \multirow{2}{*}{$\begin{array}{r}\text { Pitch } \\
\text { angle } \theta \\
\text { deg } \\
\end{array}$} & \multicolumn{3}{|c|}{$\begin{array}{l}\text { Position Shift of article due } \\
\text { to Pitch angle }(\mathrm{mm}) \text { at }\end{array}$} & \multirow{2}{*}{$\begin{array}{l}\text { Lateral } \\
\text { Acc. } \\
\mathrm{m} / \mathrm{s}^{2}\end{array}$} & \multirow{2}{*}{$\begin{array}{l}\text { Lateral } \\
\text { Velocity } \\
\mathrm{m} / \mathrm{s}\end{array}$} & \multirow{2}{*}{$\begin{array}{l}\text { Lateral } \\
\text { shift } \\
\mathrm{mm}\end{array}$} & \multicolumn{3}{|c|}{$\begin{array}{l}\text { Clearance between article } \\
\text { body in } \mathrm{mm} \text { at }\end{array}$} \\
\hline & & & & & & Front & Tail end & Fins & & & & Canister & Guide Rail & Fins \\
\hline 0.000 & 0 & 0.000 & 0.00 & 0.000 & 0.000 & 0.0 & 0.00 & 0.0 & & & & 22.0 & 5.800 & 16.0 \\
\hline 0.153 & 0 & 0.000 & 0.00 & 0.000 & 0.000 & 0.0 & 0.00 & 0.0 & & & & 22.0 & 5.800 & 16.0 \\
\hline 0.216 & 0 & 0.000 & 0.00 & 0.000 & 0.000 & 0.0 & 0.00 & 0.0 & & & & 22.0 & 5.800 & 16.0 \\
\hline 0.265 & 4.36 & 0.000 & 0.00 & 0.000 & 0.000 & 0.0 & 0.00 & 0.0 & & & & 22.0 & 5.800 & 16.0 \\
\hline 0.276 & 4.36 & 0.047 & 2.67 & 0.001 & 0.043 & 1.4 & 0.17 & 0.1 & & & & 23.4 & 5.630 & 15.9 \\
\hline 0.294 & 4.36 & 0.125 & 7.15 & 0.003 & 0.163 & 4.3 & 0.65 & 0.4 & & & & 26.3 & 5.152 & 15.6 \\
\hline 0.310 & 4.36 & 0.198 & 11.37 & 0.005 & 0.270 & 5.7 & 1.07 & 0.6 & & & & 27.7 & 4.728 & 15.4 \\
\hline 0.327 & 4.36 & 0.268 & 15.38 & 0.006 & 0.366 & 5.7 & 1.45 & 0.9 & & & & 27.7 & 4.346 & 15.1 \\
\hline 0.353 & 4.36 & 0.385 & 22.03 & 0.011 & 0.632 & 6.5 & 2.51 & 1.5 & & & & 28.5 & 3.292 & 14.5 \\
\hline 0.368 & 4.36 & 0.450 & 25.81 & 0.013 & 0.718 & 3.6 & 2.85 & 1.7 & & & & 25.6 & 2.952 & 14.3 \\
\hline 0.383 & 4.36 & 0.514 & 29.43 & 0.014 & 0.797 & 0.3 & 3.16 & 1.9 & & & & 22.3 & 2.639 & 14.1 \\
\hline 0.388 & 0.77 & 0.518 & 29.68 & 0.014 & 0.799 & 2.0 & 3.23 & & -9.53 & -0.0543 & -0.5 & 23.5 & 3.036 & \\
\hline 0.388 & 0.76 & 0.517 & 29.64 & 0.014 & 0.799 & 3.7 & 3.23 & & -9.53 & -0.0458 & -0.5 & 25.3 & 3.046 & \\
\hline
\end{tabular}

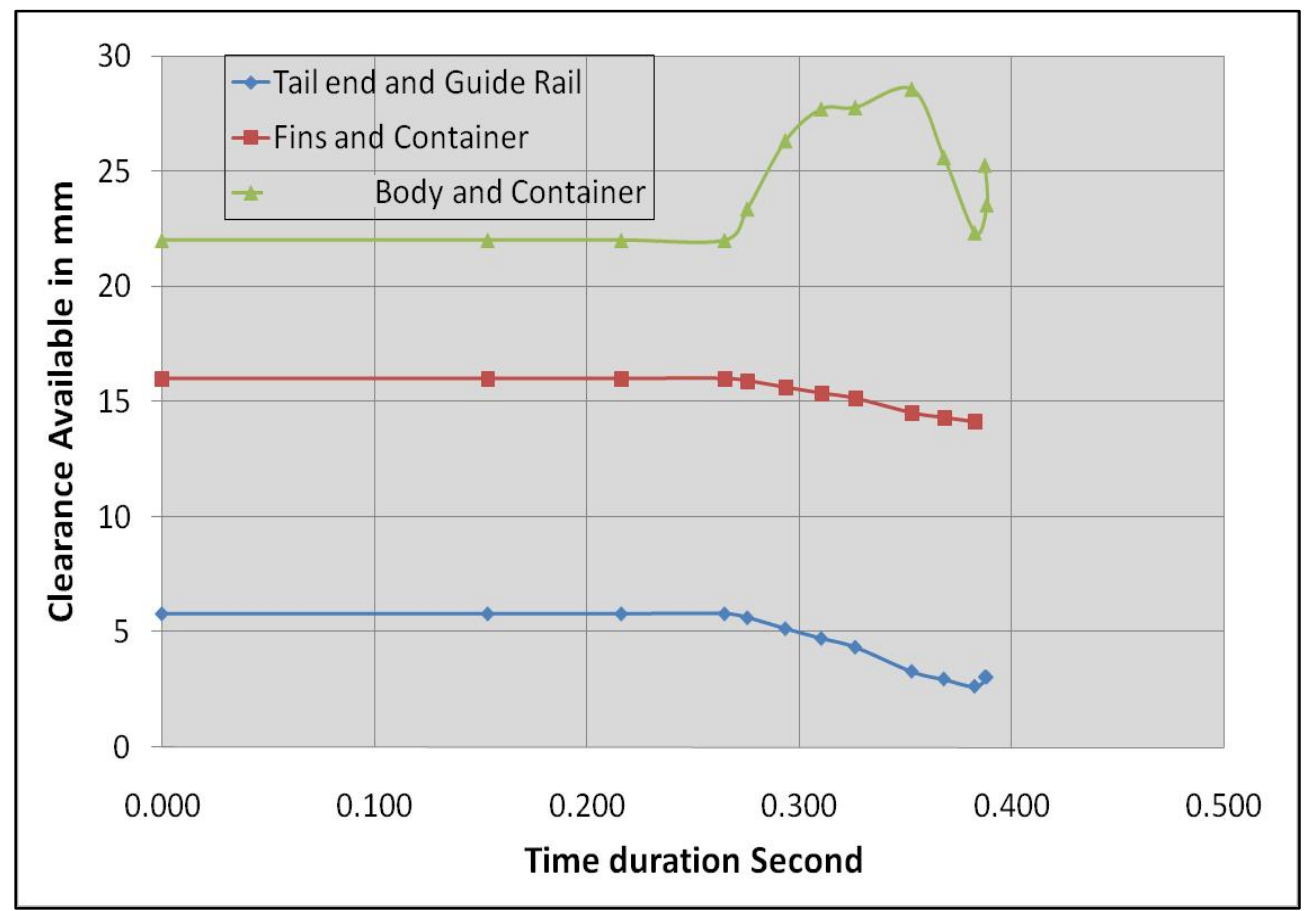

Figure 11: Clearance between Article and Launch Canister for $10^{0}$ Elevation Launch Angle.

\section{STUDIES ON EFFECT OF ARTICLE PLUME ON CANISTER THROUGH CFD ANALYSIS}

The canisterised surface to air article, when launched, generates high temperature, high pressure and supersonic gaseous medium generally termed as plume. While the article is travelling inside canister, some effect may be there due to this plume on the canister inside wall, front hatch door of the canister and adjacent canister. To study this effect, a CFD analysis was carried out while the article is at different locations within the canister. Estimation of plume load on hatch door of canister and adjacent canister were arrived at when flight vehicle comes out of canister. Modeling of fluid domain was done with canister, article with jet vanes including multispecies (plume + air). Meshing was done with Total of 2046952 Elements (Prism, Hexahedral, Tetrahedral). CFD models used are a) steady state, b) wall -adiabatic wall (heat flux transferred through its zero $\mathrm{Q}=0$ ), c) wall-isothermal wall (to calculate cold wall heat flux), d) density based solver e) viscous- turbulent (k-e std. wall fun.) 

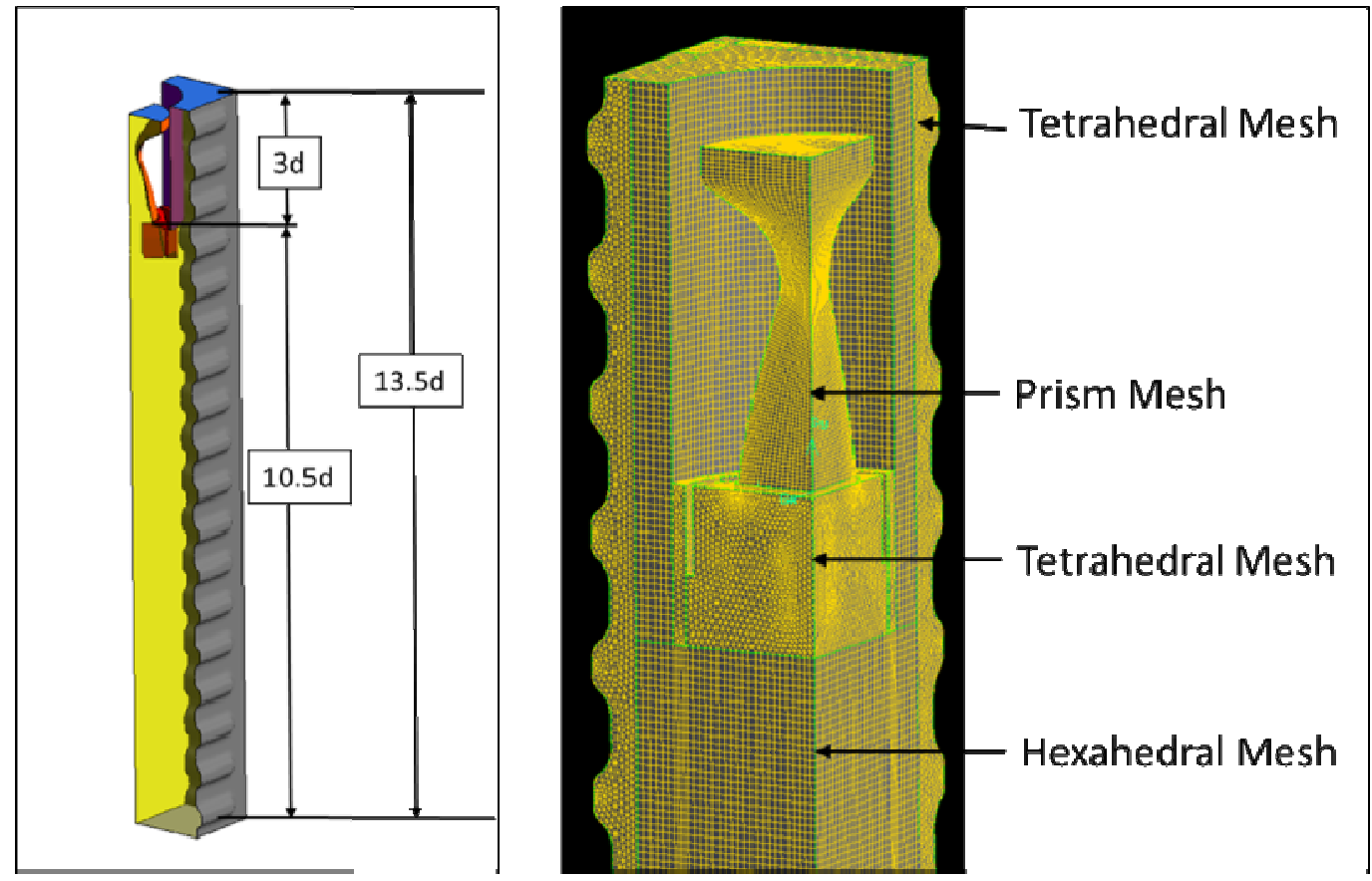

Figure 12: CFD Domain and Meshing of Embossed Canister.
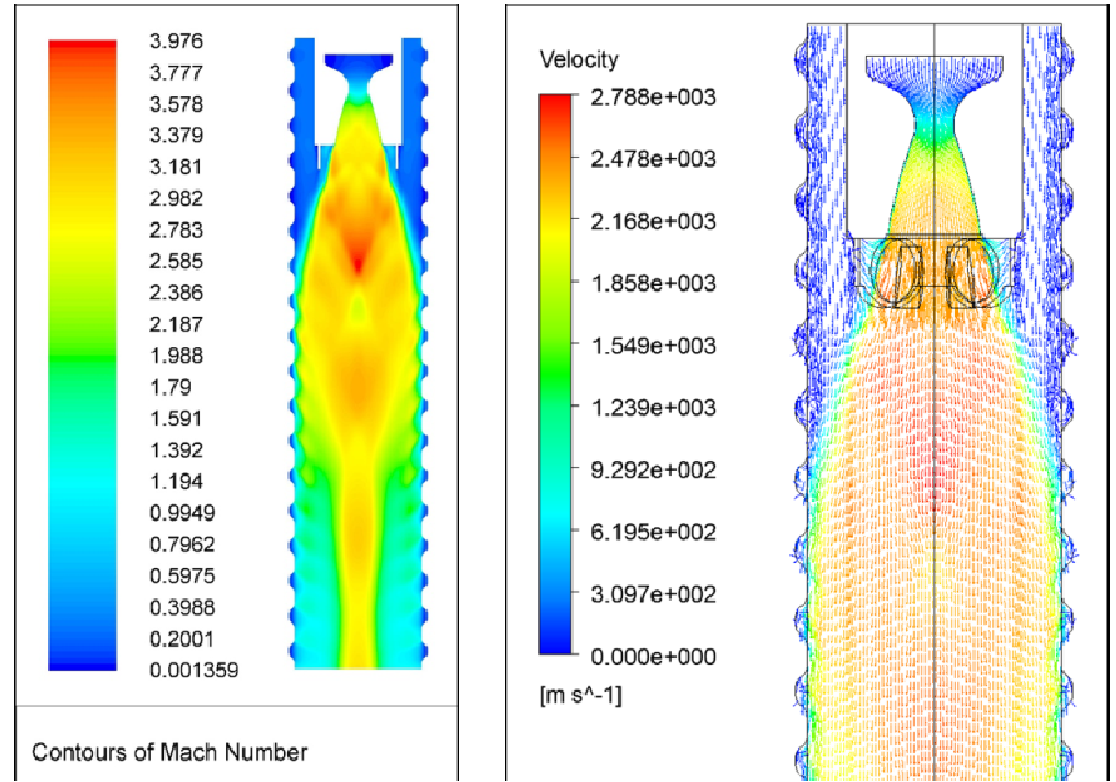

Figure 13: Contours of Mach No. and Velocity Vector at Symmetric Plane.

Maximum velocity of plume to be observed as $2812 \mathrm{~m} / \mathrm{s}$. Plume is observed to travel without any reversal effect. At article section air flows downstream side, therefore blow by flow is avoided. After some distance, mass fraction of plume is present at core only.

\subsection{Results of CFD Analysis}

Maximum positive pressure on the canister wall is observed to be 0.328 bar. Maximum negative pressure on canister wall is -0.322 bar. Hence, canister is required to be designed for both positive and negative pressure. At $\mathrm{X}=0 \mathrm{~mm}$, maximum variation of pressure is observed on canister wall since canister is square in shape and it is close to nozzle outlet. Maximum heat flux is observed to be $6.19 \mathrm{MW} / \mathrm{m} 2$. Maximum Adiabatic plume Temperature on canister wall is $2505 \mathrm{~K}$. After $0.1 \mathrm{sec}$ 
exposure of plume to the canister, temperature of canister is observed to be $440 \mathrm{~K}$ (1670C). Similarly After 0.2sec exposure of plume to the canister, temperature of canister increases to about $554 \mathrm{~K}$ (2810C).

Transient heat transfer methodology: 1D Transient Heat Transfer by FDM numerical method is used with material properties of Aluminum alloy density of $2719 \mathrm{~kg} / \mathrm{m} 3$, thermal conductivity of $202 \mathrm{~W} / \mathrm{m}-\mathrm{K}$, specific. heat of $871 \mathrm{~J} / \mathrm{kg}-\mathrm{K}$, material thickness of $2 \mathrm{~mm}, \mathrm{hf}=2808 \mathrm{~W} / \mathrm{m} 2-\mathrm{K}, \mathrm{Tf}=2505 \mathrm{~K}$, hatm $=20 \mathrm{~W} / \mathrm{m} 2-\mathrm{K}, \mathrm{Tatm}=300 \mathrm{~K}$.

\section{STUDIES ON FRONT AND REAR HATCHES}

Variety of front and rear hatch covers for launch canisters were designed by the designers earlier for different applications. For canisterised surface to air flying articles, the front and rear hatch covers require to withstand internal pressure and they are to be blown off remotely during/ before firing the article. Engineering and perfecting the designs of hatches for reliable operation involves challenging developments and validation testing.In the current design, the front and rear hatches are opened with pyro devices and locked mechanically after opening. Implementing rupturable hatches are under final stages of validation testing.

Design of a plastic dome shaped cover [4] backed by frangible glass ribs were blown with the help of linear shaped explosive charge and detonator. A single piece protective cover is ejected when the nose of article presses the cover. The design is found to be suitable for smaller size launch canisters. A canister for a foldable-wing article serving as a duel function of providing an environmental container and a launching tube is conceived by Charles B. Haas et al [3]. Upper and lower guide rails are provided in the canister for supporting the article during storage and during launch, and a pair of horizontal guides are attached one each to the sides of the canister to serve as stiffeners and guides for folded article wings. Frangible covers are provided for closing the front and aft of the canister and locking devices are provided on the canister to lock the article in position until launch.

A cover for sealing the canister with an inner layer of tempered glass bonded by an adhesive to an outer layer of structural foam with score marks is designed by David Lynn Hunn et al [9]. Upon launch of the munitions the inner layer of tempered glass breaks into numerous fragments which remain bonded to the outer layer of scored foam by the adhesive layer. The outer layer of foam then breaks along its score marks into two or more pieces that have pieces of the inner layer of glass bonded thereto. The pieces of foam with glass fragments bonded thereto are then blown out and away from the canister.

AkeJansson et al [8] designed the article launch tube cover comprising a hollow insert made of a light weight foam material divided into radial segments. When the article is launched it tends to displace the cover and direct the segments in a radial direction because of positive air pressure imparted to the concave inside surfaces of the cover by the article. A coating is applied on the outer surfaces of the cover to prevent icing and/or electromagnetic interference.

\section{MANUFACTURING METHODOLOGY ADOPTED}

The aim of any design process is to develop a manufacturing process with the following objectives like meet all the functional requirements, which is simple in manufacturing, to be able to use easily available materials, which should be able to reduce weld distortions during fabrication of the structure, should be able to maintain the geometrical tolerances and which is cost effective. Initially the sheet metal is embossed using a die punch on a Hydraulic press, then it is bended at two locations to form a inverted $\mathrm{U}$ type top section. Similarly matching $\mathrm{U}$ type bottom section is made. There are pads provided at the top of canister for mounting of guiderail. The guide rail enables smooth sliding of the article lugs during loading of article and article 
launch. Also there are pads provided for mounting of the wing rails on the vertical side walls of the canister. The wing rails enable provides guidance and sliding of folded article wings and fins. The guide rail pads are welded to the top inverted $\mathrm{U}$ section and wing rail pads are welded to the vertical walls of the top $\mathrm{U}$ section. There are canister mounting frames which enables mounting of canister on the launch beam as well as enables stacking of the canisters one above the other which are welded to the canister embossed sheets at the front and rear.

\section{CONCLUSIONS}

The design and analysis of article launch canister presented in this papershow that the launch canister meets the stated functionality and objectives. The novel construction method (with plane Aluminum sheet metal inside reinforced with corrugated sheet outside, produced less deflection due to internal pressure and found to meet various transporting, handling, environmental and operating loads. The launch canister thus realized has been successfully used in the flight tests confirming the adequacy of design at system level.

\section{ACKNOWLEDGMENT}

The authors thank Director, Research and Development Establishment (Engineers), Pune and Electro-Mechanical Systems Group team for the valuable contributions and suggestions.

\section{REFERENCES}

1. Cun-Gui Yu, Tong-Sheng Sun, Guang-Yuan Xiao, "Study on creep performance of launch canister under long term storage," Transactions of the Canadian Society for Mechanical Engineering, Aug 2018

2. JH Wu, WT Wang, TY Kam, "Failure analysis of frangible laminated composite canister cover," Proceedings of the institution of mechanical engineers, Part G: Journal of Aerospace Engineering, 1999

3. Charles B. Haas, Richard E. Taylor, David E. Crockett; James F. Miller, Howard R. Paul, Charles J. Reid, "Article launching canister," United States Patent no 3769876, Nov 6, 1973

4. Richard A. Mussey, “Launch tube closure,” United States Patent no 4301708; Nov 24, 1981

5. Bernard J. Kuchta, James L. Gardner," Extended canister flythrough protective cover” United States Patent no 6123005; Sep 26, 2000

6. R.A.Peshkov, A.V. Erpalov, “Developing Methods for Calculating Gas-Dynamic Parameters in Launch Canister during the Article Launch,” Proceedings of the $5^{\text {th }}$ International Conference on Industrial Engineering (ICIE 2019), pp765-773

7. MJ Miller, PC Woods, “Article canister gated obturator,” United States Patent no 9874420; Jan 23, 2018

8. AkeJansson, "Launch tube protective cover," United States Patent no 7954412 B2; Jun 7, 2011

9. David Lynn Hunn, "Device and method for sealing a munition within Launch Canister until munition launch," United States Patent no 5993921; Nov 30,1999 
10. Bryan Bowen, Anthony Machell, Terence Edward Kavanagh, Denis George Turner, “Article Canister,” United States Patent no 8973480B2; Mar 102015

11. David L Fox, “Modulararticle launching assembly," United States Patent no 7854189; Dec21, 2010 
